\title{
Correction to: Associations Between Two Measures of Trunk Muscular Endurance Among Male Law Enforcement Officers
}

\author{
J. Jay Dawes ${ }^{1,2}\left(\mathbb{D} \cdot\right.$ Cody A. Stahl ${ }^{1,2} \cdot$ Robert G. Lockie $^{3} \cdot$ Jan E. Redmond ${ }^{4} \cdot$ Charlie Kornhauser $^{5} \cdot$ Ryan J. Holmes $^{5}$. \\ Robin M. Orr ${ }^{6}$
}

Published online: 29 October 2020

(c) Beijing Sport University 2020

\section{Correction to: Journal of Science in Sport and Exercise https://doi.org/10.1007/s42978-020-00073-2}

The original version of this article, published on August 7, 2020, contained a mistake. The affiliations were incorrect. The correct affiliations of the authors are given below.

${ }^{1}$ School of Kinesiology, Applied Health and Recreation, Oklahoma State University, Stillwater,OK, USA

${ }^{2}$ Tactical Fitness and Nutrition Laboratory, Oklahoma State University, Stillwater, OK, USA

${ }^{3}$ Department of Kinesiology, California State University, Fullerton, Fullerton CA, USA
${ }^{4}$ United States Army Research Institute of Environmental Medicine, Natick, MA, USA

${ }^{5}$ Colorado State Patrol, Golden, CO, USA

${ }^{6}$ Tactical Research Unit, Bond University, Robina, QLD, AUS

The original article can be found online at https://doi.org/10.1007/ s42978-020-00073-2.

J. Jay Dawes

jay.dawes@okstate.edu

1 School of Kinesiology, Applied Health and Recreation, Oklahoma State University, Stillwater, OK, USA

2 Tactical Fitness and Nutrition Laboratory, Oklahoma State University, Stillwater, OK, USA

3 Department of Kinesiology, California State University, Fullerton, Fullerton, CA, USA

4 United States Army Research Institute of Environmental Medicine, Natick, MA, USA

5 Colorado State Patrol, Golden, CO, USA

6 Tactical Research Unit, Bond University, Robina, QLD, Australia 